\title{
Very Early Brain Damage Leads to Remodeling of the Working Memory System in Adulthood: A Combined fMRI/ Tractography Study
}

\author{
Seán Froudist-Walsh, ${ }^{1}$ Vyacheslav Karolis, ${ }^{1}$ Chiara Caldinelli, ${ }^{1}$ Philip J. Brittain, ${ }^{1}$ Jasmin Kroll, ${ }^{1}$ \\ Elisa Rodríguez-Toscano, ${ }^{1,3}$ Marcello Tesse, ${ }^{1}$ Matthew Colquhoun, ${ }^{1}$ Oliver Howes, ${ }^{1,4}$ Flavio Dell'Acqua, ${ }^{2}$ \\ Michel Thiebaut de Schotten, ${ }^{5,6}$ Robin M. Murray, ${ }^{1}$ Steven C.R. Williams, ${ }^{2}$ and Chiara Nosarti ${ }^{1,7}$ \\ ${ }^{1}$ Department of Psychosis Studies, ${ }^{2}$ Department of Neuroimaging, Institute of Psychiatry, Psychology and Neuroscience, King's Health Partners, King's \\ College London, London WC2R 2LS, United Kingdom, ${ }^{3}$ Department of Child and Adolescent Psychiatry, Hospital General Universitario Gregorio Marañón, \\ Centro de Investigación Biomédica En Red de Salud Mental, El Instituto de Investigación Sanitaria del Hospital Gregoria Marañón, School of Medicine, \\ Universidad Complutense, 28009 Madrid, Spain, ${ }^{4}$ Medical Research Council, Clinical Sciences Centre, Institute of Clinical Sciences, Hammersmith Hospital \\ Campus, Imperial College London, London W12 0HS, United Kingdom, ${ }^{5}$ Centre National de la Recherche Scientifique, Unité Mixte de Recherche 7225, \\ Inserm, Universite Pierre et Marie Curie-Paris 6, UMR_S 1127, Centre de Recherche de l'Institut du Cerveau et de la Moelle épinière, GH Pitié-Salpêtrière, \\ 75013 Paris, France, ${ }^{6}$ Natbrainlab, Brain and Spine Institute, 75013 Paris, France, and ${ }^{7}$ Centre for the Developing Brain, Division of Imaging Sciences and \\ Biomedical Engineering, King's Health Partners, King's College London, St. Thomas' Hospital, London WC2R 2LS, United Kingdom
}

The human brain can adapt to overcome injury even years after an initial insult. One hypothesis states that early brain injury survivors, by taking advantage of critical periods of high plasticity during childhood, should recover more successfully than those who suffer injury later in life. This hypothesis has been challenged by recent studies showing worse cognitive outcome in individuals with early brain injury, compared with individuals with later brain injury, with working memory particularly affected. We invited individuals who suffered perinatal brain injury (PBI) for an fMRI/diffusion MRI tractography study of working memory and hypothesized that, 30 years after the initial injury, working memory deficits in the PBI group would remain, despite compensatory activation in areas outside the typical working memory network. Furthermore we hypothesized that the amount of functional reorganization would be related to the level of injury to the dorsal cingulum tract, which connects medial frontal and parietal working memory structures. We found that adults who suffered PBI did not significantly differ from controls in working memory performance. They exhibited less activation in classic frontoparietal working memory areas and a relative overactivation of bilateral perisylvian cortex compared with controls. Structurally, the dorsal cingulum volume and hindrance-modulated orientational anisotropy was significantly reduced in the PBI group. Furthermore there was uniquely in the PBI group a significant negative correlation between the volume of this tract and activation in the bilateral perisylvian cortex and a positive correlation between this activation and task performance. This provides the first evidence of compensatory plasticity of the working memory network following PBI.

Key words: fMRI; perinatal brain injury; plasticity; spherical deconvolution; tractography; working memory

Significance Statement

Here we used the example of perinatal brain injury (PBI) associated with very preterm birth to study the brain's ability to adapt to injury sustained early in life. In adulthood, individuals with PBI did not show significant deficits in working memory, but exhibited less activation in typical frontoparietal working memory areas. They also showed a relative overactivation of nontask-specific brain areas (perisylvian cortex) compared with controls, and such activation was negatively correlated with the size of white matter pathways involved in working memory (dorsal cingulum). Furthermore, this "extra" activation was associated with better working memory performance and could represent a novel compensatory mechanism following PBI. Such information could inform the development of neuroscience-based cognitive interventions following PBI. 


\section{Introduction}

Despite great clinical effort, babies born very preterm (VPT; $<32$ weeks of gestation) are vulnerable to prematurity-related brain injury (PBI; McCrea and Ment, 2008; Ballabh, 2014), which can cause long-term cognitive difficulties for affected individuals (Luu et al., 2009). A growing interest in studying the long-term effects of PBI stems from the discovery that plastic changes in the brain and improvements to affected functions can occur even many years after brain injury (Kleim and Jones, 2008). The majority of research into the mechanisms of chronic-stage recovery from brain injury has focused on stroke patients, in whom agerelated degenerative processes are likely to have already begun (Sudlow and Warlow, 1997; Sowell et al., 2003). The possibilities for successful reorganization of brain resources could be even greater following very early brain injury, as affected individuals may take advantage of "critical periods," during which the brain is purported to have a higher capacity for plastic reorganization (Hensch, 2004). One unique and potentially crucial difference between PBI and later injury is the fact that higher-order cognitive networks are yet to fully form at the time of PBI (Doria et al., 2010).

By focusing on how specific cognitive networks adapt to PBIrelated anatomical constraints, we may learn general principles of brain reorganization by which we can guide plasticity-promoting interventions, such as those successfully implemented in stroke patients (Wolf et al., 2006; Berthier and Pulvermüller, 2011). Working memory is a cognitive function that is commonly affected in children who have suffered PBI (Ross et al., 1996; Woodward et al., 2005; Beauchamp et al., 2008; Anderson et al., 2010). This function is critical to everyday functioning (Kane et al., 2007) and may underlie academic difficulties (Mulder et al., 2010). Little is known, however, about the degree of working memory disruption in adulthood, the neuroanatomical substrates of working memory following PBI, or possible mechanisms by which the brain may adapt following early insults.

Here, using functional MRI (during performance of an $n$-back working memory task) and damped Richardson-Lucy spherical deconvolution tractography (Dell'acqua et al., 2010), we investigated whether PBI induces functional and structural reorganization of the working memory system by adulthood. This method allowed us to investigate the hindrance-modulated orientational anisotropy (HMOA), a sensitive tract-specific index of tract microstructure and organization (Dell'Acqua et al., 2013), in areas of crossing fibers. HMOA has an advantage over traditional voxel-based measures, such as fractional anisotropy (FA), as it does not assign values to an average of all tracts within a voxel, but separately to each tract passing through a voxel. This is important

Received Nov. 21, 2014; revised Sept. 22, 2015; accepted 0ct. 12, 2015.

Author contributions: S.F.-W., O.H., M.T.d.S., R.M.M., S.C.R.W., and C.N. designed research; S.F.-W., V.K., C.C., P.J.B., J.K., E.R.-T., M.T., M.C., and C.N. performed research; F.D. contributed unpublished reagents/analytic tools; S.F.-W., V.K., C.C., E.R.-T., M.T., M.T.d.S., and C.N. analyzed data; S.F.-W., V.K., C.C., P.J.B., J.K., M.C., O.H., F.D., M.T.d.S., R.M.M., S.C.R.W., and C.N. wrote the paper.

This work was supported by the March of Dimes (\#12-FY11-206) and the Medical Research Council (MRC MR/ K004867/1). We thank our participants and the Preterm Research Group (pretermresearch.org) for their support during this research and Dr. Elias Mouchlianitis for very helpful discussions. We also thank the National Institute for Health Research (NIHR) Biomedical Research Centre at South London and Maudsley NHS Foundation Trust and King's College London for their support of the neuroimaging facilities used in this study.

The authors declare no competing financial interests.

This article is freely available online through the J Neurosci Author Open Choice option.

Correspondence should be addressed to Seán Froudist-Walsh, Department of Neuroscience, Icahn School of Medicine at Mount Sinai, New York, NY 10029. E-mail: froudiss@tcd.ie.

D0I:10.1523/JNEUROSCI.4769-14.2015

Copyright (c) 2015 Froudist-Walsh et al.

This is an Open Access article distributed under the terms of the Creative Commons Attribution License Creative Commons Attribution 4.0 International, which permits unrestricted use, distribution and reproduction in any medium provided that the original work is properly attributed. as $60-90 \%$ of voxels (and probably all tracts) in the brain are affected by crossing fibers (Jeurissen et al., 2013), thus making voxel-average methods hard to interpret, particularly in tracts that are greatly affected by crossing fibers, including the superior longitudinal fasciculus (SLF).

We hypothesized a reduction in activation in the prefrontal cortex and the medial posterior parietal cortex bilaterally, areas of the working memory network that display developmental delay following PBI (Owen et al., 2005; Nosarti et al., 2008). We also hypothesized increased activation in alternative cortical areas capable of performing similar computations (Salvan et al., 2014) and that the level of functional reorganization would be related to structural alteration to the dorsal cingulum tract, as this tract passes close by the lateral ventricles (where neonatal hemorrhage often occurs in individuals with $\mathrm{PBI}$ ) and connects key medial working memory structures. We tested the specificity of any dorsal cingulum effects using a double-control approach, analyzing (1) a tract that is likely to be affected by PBI, but is unlikely to be directly involved in working memory (ventral cingulum) and (2) tracts that are unlikely to be directly affected by PBI, but are likely to be involved in working memory (SLF 1-3). We expected that VPT individuals with no documented PBI (VPT-N) would demonstrate quantitatively different activation from controls, but would not require recruitment of novel areas to perform the task, as would be observed in the PBI group (Just and Varma, 2007). We observed a discrepancy between verbal and performance IQ scores in the PBI group. Thus, in an exploratory analysis, we assessed the IQ dominance (IQD) of the three groups and the possible relationship between this index and working memory performance and brain activation.

\section{Materials and Methods Participants fMRI study}

PBI group. Twenty participants (10 females) who had evidence of neonatal periventricular hemorrhage (grade I-IV) and/or ventricular dilatation according to ultrasound diagnosis within $5 \mathrm{~d}$ of birth were recruited for the fMRI study from a cohort of individuals born very preterm admitted to the neonatal unit at University College Hospital, London, between 1979 and 1985.

Periventricular hemorrhage was classified as hemorrhage into the germinal layer or lateral ventricles (Stewart et al., 1983). Ventricular dilatation was classified as clear dilatation of one or both lateral ventricles with CSF, although not sufficient to meet the conditions for a diagnosis of hydrocephalus. The maximum ventricular width was measured in the coronal plane at the level of the foramen of Monro (Levene, 1981).

Exclusion criteria included severe head injury, stroke, multiple sclerosis, epilepsy, severe visual impairment, hearing and/or motor impairment, and pregnancy for females. See Table 2 for demographic information on all groups.

VPT-N group. Twenty-one individuals born very preterm (10 females), recruited from the same cohort described above, without evidence of perinatal brain injury, were also studied. Exclusion criteria were the same as the PBI group.

Term-born controls. Forty-six term born control participants (29 females) were recruited from previous studies and on-line advertisements. Inclusion criteria were full-term birth (38-42 weeks) and birth weight $>2500$ g. Exclusion criteria included any history of neurological conditions including meningitis, head injury, and cerebral infections.

\section{Diffusion MRI tractography study}

To increase our sensitivity to detect structural differences between groups, we increased the size of our cohort for the diffusion MRI tractography study. A further 17 individuals born very preterm with PBI, 15 VPT-N individuals, and 34 term-born control participants were recruited for the structural imaging study, so that the final groups for the structural study included 39 individuals with PBI, 36 individuals born 
very preterm without such injury (VPT-N), and 80 controls. The additional participants did not differ from the participants that completed the fMRI study in chronological age at assessment, gestational age at birth, birth weight, or IQ for any of the three groups (all $p>0.14$ ). There was a difference in gender distribution in the control group, with more males in the diffusion MRI cohort $\left(\chi^{2}=4.565, p=0.033\right)$.

Ethical approval for the study was obtained from King's College London Psychiatry, Nursing and Midwifery Research Ethics Subcommittee, in compliance with national legislation and the code of ethical principles for Medical Research Involving Human Subjects of the World Medical Association (Declaration of Helsinki). Written informed consent was obtained from all participants.

\section{MRI acquisition}

For the fMRI scan, 186 gradient-echo echo-planar images (TR/TE = $2000 / 30 \mathrm{~ms}$; flip angle, $75^{\circ}$; matrix, $64 \times 64$ ) were acquired on a 3 tesla GE Signa MR scanner (GE Healthcare) at the Institute of Psychiatry/Maudsley Hospital, King's College London. Each whole-brain image contained 39 noncontiguous slices of $3.5 \mathrm{~mm}$ thickness separated by a distance of $0.5 \mathrm{~mm}$, and with in-plane voxel resolution of $3.75 \times 3.75 \mathrm{~mm}^{2}$. For the diffusion-weighted imaging, 60 contiguous near-axial slices were acquired with no gap and the following parameters: rostrocaudal phase encoding; $b$ value $=1300 \mathrm{~s} / \mathrm{mm}^{2} ;$ TE $=105 \mathrm{~ms}$; voxel size, $2.4 \mathrm{~mm}^{3} ; 32$ diffusion-weighted directions and 4 nondiffusion weighted volumes, using a spin-echo EPI sequence. Peripheral cardiac gating was applied, with an effective TR of 20/30 R-R intervals.

$\mathrm{T} 1$-weighted images were also acquired $(\mathrm{TR} / \mathrm{TE} / \mathrm{TI}=7.1 / 2.8 / 450 \mathrm{~ms}$; matrix, $256 \times 256$ ), allowing for 196 slices with no gap and an isotropic resolution of $1.1 \times 1.1 \times 1.1 \mathrm{~mm}^{3}$.

\section{Task}

Before scanning, all participants were trained on the task (with a different sequence of letters) until comfortable with the rules. During the scan, participants were given a button box and were presented with visual stimuli (letters) through a two-mirror system. The task involved a control (not targeting working memory) condition, where participants had to press a button with their index finger every time they were presented with the letter " $X$ " on the screen. The active task conditions were the one-back, two-back, and three-back, which place increasing amounts of strain on the working memory system. In these conditions, participants were requested to respond by pressing the button every time the letter visually presented to them was the same as the one presented one, two, or three letters previously, respectively. Stimuli were presented every $2 \mathrm{~s}$. Each stimulus block contained three target stimuli and 11 nontarget stimuli. Each condition was repeated three times, blocks were presented in a pseudorandom order and, before each new block, an instruction was given telling the participant which condition was next (for more details on the N-back working memory paradigm, see Owen et al., 2005).

Task performance and reaction times inside the scanner were recorded and individual scores were used to calculate $d^{\prime}$, a bias-free measure that takes into account both hit rate (or omission errors) and false alarms (commission errors; Haatveit et al., 2010). Corrected recognition hits were also calculated as the proportion of correct hits minus the proportion of false alarms.

\section{MRI preprocessing}

fMRI data preprocessing was performed using the fMRI Expert Analysis Tool (FEAT) from the FSL's [FMRIB (Functional Magnetic Resonance Imaging of the Brain) Software Library; version 6.0.0; Woolrich et al., 2009; Jenkinson et al., 2012]. Images were motion-corrected using mcFLIRT (Motion Correction-FMRIB Linear Image Registration Tool; Jenkinson et al., 2002), slice-time corrected using Fourier-space timeseries phase-shifting, skull stripped using Brain Extraction Tool (BET; Smith, 2002), and smoothed using a Gaussian kernel of FWHM $=5 \mathrm{~mm}$. The $4 \mathrm{D}$ dataset was grand-mean intensity normalized by a single multiplicative factor and was high-pass filtered $(\sigma=31 \mathrm{~s})$.

As part of the denoising process, independent component analysis of each participant's native space preprocessed data fMRI was performed using Me- lodic (version 3.13; Beckmann, 2004), where the number of dimensions was estimated using Laplace's method for approximation of the Bayesian evidence of the model order (Minka, 2000; Beckmann, 2004).

The components of 20 participants ( $10 \mathrm{VPT}$ and 10 controls) were then manually divided into signal and noise components by the first author according to the guidelines set out by Kelly et al. (2010). These manually denoised data were then used as training data for FMRIB's independent component analysis (ICA)-based X-noisifier (FIX; http://fsl.fmrib.ox.ac.uk/ fsl/ fslwiki / F IX), which learns to automatically classify ICA components from each subject's data into brain-derived BOLD signal components and structured noise components (Marcus et al., 2013; Salimi-Khorshidi et al., 2014). Leave-one-out testing was then run to compare the automatic classification to the manual classification. FIX performed with 100\% accuracy in all cases. Visual checks confirmed the very high accuracy of FIX's classification. FIX was then used to identify noise components in all of the study participants. The time courses of the noise components and motion parameters were then regressed out of the data.

\section{Normalization}

We sought to optimize our normalization protocol to enable comparison of individuals with abnormal brain anatomy with control data. We used boundary-based registration (BBR; Greve and Fischl, 2009) as implemented in FSL to register each individual's fMRI data to their t1-weighted image. This technique extracts the surfaces from the t1-weighted image, and then aligns the fMRI data to the t1-weighted data by maximizing the intensity gradient across tissue boundaries. This method has been shown to be more accurate and robust to signal inhomogeneities than traditional intrasubject registration algorithms (Greve and Fischl, 2009).

A study-specific t1-weighted template was created using 39 VPT-born participants (comprising 18 individuals from the PBI group and 21 from the VPT-N group) and 39 controls. This was done using the Greedy symmetric diffeomorphic normalization (GreedySyN) approach (Avants et al., 2011). We used this approach to normalization as it has been shown to be the joint top-performing normalization method in a comparison of 14 common methods (Klein et al., 2009). The template was created using the buildtemplateparallel.sh script distributed with the Advanced Normalization Tools software (http://stnava.github.io/ANTs/; Avants et al., 2010). After an initial affine template was created, four iterations of the nonlinear template creation were performed, to allow template convergence. A t1-weighted image-to-template mapping was then computed for each participant using ANTS/GreedySyN. This mapping was then composed with the affine fMRI-to-tl-weighted-image mapping obtained with BBR. The combined and subject-specific fMRI-to-template mapping was then applied to each individual's fMRI data using only one interpolation of the data.

A gray matter template mask was then created using BET brain extraction (Smith et al., 2002), FMRIB's Automated Segmentation Tool (FAST) gray/white/CSF segmentation (Zhang et al., 2001), and FMRIB's Integrated Registration and Segmentation Tool (FIRST) subcortical segmentation (Patenaude et al., 2011) on the custom template. FIRST provides much more accurate subcortical segmentation than traditional segmentation algorithms, such as FAST (Patenaude et al., 2011). Thus we combined the outputs of FIRST and FAST to make a combined, binarized cortical and subcortical gray matter mask, within which the grouplevel statistical analysis was performed.

\section{fMRI statistical analysis}

fMRI data analysis was performed using FSL's FEAT (version 6.0.0). Time series analysis was performed using FMRIB's Improved Linear Model, with local autocorrelation correction (Woolrich et al., 2001). Higher-level analysis was performed using FMRIB's Local Analysis of Mixed Effects (FLAME) stage $1+2$. FEAT incorporates Markov Chain Monte Carlo (MCMC) estimation of the random effects at each voxel (Woolrich et al., 2004). The Bayesian structure of FLAME enabled us to model and estimate different group-level variances and, importantly, to carry up the first-level individual fixed-effects variances. Higher-level parameter estimates and mixed-effects variances were fitted using a fast approximation to the final estimation. Mixed-effects variance in the 
near-threshold voxels was then processed using MCMC estimation, to which a general $t$ distribution was fit. Hypothesis testing was performed on the fitted $t$ distribution using this estimation of mixed-effects variance. $Z$-statistic images were thresholded using a $Z>2.3$ and an FWEcorrected cluster threshold of $p<0.05$ (Worsley, 2001).

We analyzed the data using a linear contrast, searching for areas that showed differential activation as working memory demands increased with the effects of the "Is it X?" visuomotor baseline condition used as the implicit baseline. As the two-back condition is the middle condition in a three-point linear comparison, this design in practice contrasts activation during the complex three-back working memory condition (which includes the key cognitive control and extended phonological loop aspects of working memory; Baddeley, 2003) with activation during the simpler one-back condition, which does not engage the central executive component of working memory and could be better described as a "short-term memory" task. The one-back task acted as a high-level baseline condition that allowed us to focus on the key cognitive components of working memory. Unless otherwise stated, all fMRI results pertain to the three-versus-one-back contrast.

We additionally repeated the above analyses, using sex as a covariate of no interest.

\section{Analysis of functional activation patterns across working memory difficulty levels}

To further probe the patterns of activation across levels of working memory difficulty, we analyzed the trends underlying the activation patterns in areas that significantly differed between the PBI and term-born control groups using repeated-measured ANOVA. We then used polynomial contrasts to assess whether the activation patterns had significant linear and quadratic terms (also known as trend analysis). These analyses allow us to analyze whether activation patterns increase or decrease in a linear or quadratic manner across the three levels of increasing working memory difficulty.

\section{Structural MRI processing}

Cortical and subcortical reconstruction was performed using FreeSurfer (Fischl, 2012). This involved removal of nonbrain tissue using a hybrid watershed/surface deformation procedure (Ségonne et al., 2004), segmentation of subcortical structures and ventricles (Fischl et al., 2002), intensity normalization, tessellation of the white/gray matter border, and topology correction to remove any "holes" or "handles" in the cortical surface (Fischl et al., 2001; Ségonne et al., 2007). The initial white/gray surface was then progressively deformed until it encountered areas of sharpest image contrast, which indicate the borders between white matter and gray matter and between gray matter and CSF (Dale et al., 1999). The cerebral cortex was then automatically parcellated using geometric information and inference from a handdissected training dataset (Fischl et al., 2004).

\section{Diffusion-weighted MRI processing}

Diffusion-weighted and b0 images were processed as follows. Brain masks were created using FSL's BET (Smith, 2002). Motion and eddycurrent correction was performed on the masked diffusion data using ExploreDTI (Leemans et al., 2009). A spherical deconvolution approach was chosen to allow for the estimation of multiple fiber directions within a single voxel (Tournier et al., 2004). This was calculated using a damped version of the Richardson-Lucy algorithm (Dell'acqua et al., 2010). We optimized parameters to find the best balance between resolving multiple fiber directions and creating minimal spurious (false positive) fiber orientation distribution (FOD) components. After carefully altering the parameters and testing on multiple subjects, we used a regularization threshold of $\eta=0.02$, a fiber response function $=2,300$ algorithm iterations, and regularization parameter $v=20$. Fiber orientation estimates were taken from the orientation of the peaks of the FOD profile. We applied an "absolute" (equal to four times the amplitude of a spherical FOD obtained from a gray matter voxel) and a "relative" threshold (equal to $7 \%$ of the amplitude of the maximum amplitude of the FOD at that voxel) at each voxel to remove the general noise floor and surviving noise local maxima, respectively.

\section{Tractography algorithm and dissections}

Whole-brain tractography was performed in native diffusion space using each FOD peak (that survived thresholding) as a seed. Fiber orientation streamlines were propagated using Euler integration with a step-size of 1 $\mathrm{mm}$. Propagation stopped if the track reached an FOD peak that did not survive thresholding, or if the angle between two successive steps exceeded $60^{\circ}$. If, while propagating a streamline from one voxel to the next, $>1$ FOD lobe in the next voxel survived thresholding, propagation of the tract continued along the lobe with the lowest angular distance from the current voxel's FOD lobe. Spherical deconvolution, fiber-orientation estimation, and tractography were performed using in-house software written in Matlab 7.8 (http://www.mathworks.co.uk/products/matlab/; Dell'Acqua et al., 2013).

Due to our hypothesis, the dorsal cingulum was the focus of our tractography study. The ventral cingulum, which connects parahippocampal structures to the posterior cingulate and medial parietal structures, is not thought to be involved in working memory, and was dissected to act as a control tract. We hypothesized that there would be a group difference in tract volume due to its location close to the lateral ventricles, but that this would not be related to the reorganization of the working memory system.

We additionally analyzed the SLFs. These frontoparietal tracts have previously been associated with working memory function, but lie distant from the lateral ventricles, and are thus unlikely to be directly affected by periventricular hemorrhage. By analyzing these tracts, we show that not all working memory tracts are reduced in volume following PBI.

We thus have a double control for the dorsal cingulum tract: (1) a tract that is likely to be affected by PBI, but is unlikely to be directly involved in working memory (ventral cingulum) and (2) tracts that are unlikely to be directly affected by PBI, but are likely to be involved in working memory (SLF 1-3).

Virtual dissections of the dorsal and ventral cingulum were manually performed in native diffusion space in TrackVis (trackvis.org) using a tworegion method for the dorsal and ventral cingulum, with artifactual fibers carefully removed through the use of a manually drawn exclusion region.

To further examine the role of the white matter connections in working memory function following PBI, we then dissected the SLF. This tract system connects frontal and parietal cortex laterally to the dorsal cingulum (Fig. 1) and has been described as a three-tract system in man, mirroring the monkey's neuroanatomy (Thiebaut de Schotten et al., 2012). According to Thiebaut de Schotten and colleagues, "In humans, the first branch of the superior longitudinal fasciculus (SLF1) connects the superior parietal lobule and precuneus (BA 5 and 7) with the superior frontal gyrus (BA 8, 9 and 32) and perhaps to some anterior cingulate areas (BA 24). The second branch (SLF2) originates in the anterior intraparietal sulcus and the angular gyrus (BA 39) and terminates in the posterior regions of the superior and middle frontal gyrus (BA 6, 8, 9). The third branch (SLF3) connects the intraparietal sulcus and the inferior parietal lobule to the inferior frontal gyrus (BA 44, 45, 47)" (Thiebaut de Schotten et al., 2012).

As precise manual definition of cortical landmarks can be challenging and time consuming using diffusion-weighted scans, we used FreeSurfer to define the cortical landmarks on the t1-weighted images (Fischl, 2012). The whole-brain tracks obtained using damped Richardson-Lucy spherical deconvolution tractography for each individual were then registered to the FreeSurfer structural scan using boundary-based registration (Greve and Fischl, 2009; from a contrast-inversed FA image) and the track_transform command (part of the Diffusion Toolkit package; trackvis.org). Diffusionto-FreeSurfer registrations were checked manually for accuracy.

The regions of interest used for defining the SLF 1, SLF 2, and SLF 3 are described in Table 1.

HMOA, a novel measure of microstructural white matter integrity was extracted for each tract (Dell'Acqua et al., 2013). HMOA has several advantages over traditional diffusion MRI measurements, such as FA. HMOA represents the absolute amplitude of each lobe fiber orientation distribution. Thus, within voxels that contain multiple fiber orientations (i.e., those with crossing fibers), each tract within the voxel will be assigned distinct HMOA values. When generating average HMOA values along a tract, only the HMOA lobe included in the tract of interest contributes to the value of the tract. The decision criterion for the inclusion of individual FOD lobes in a tract is described above.

All tractography comparisons are also presented after adjusting for sex. 


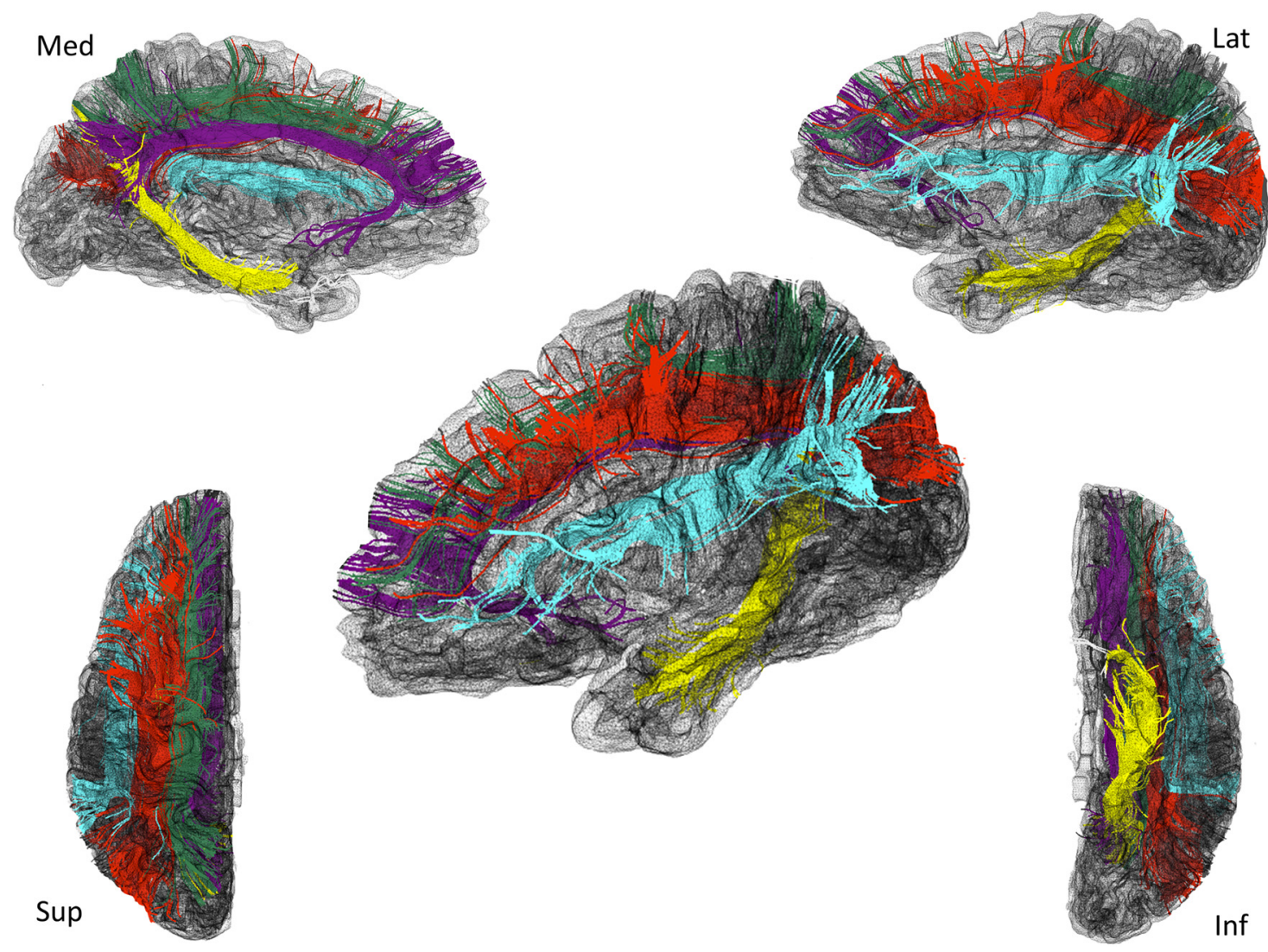

Figure 1. White matter tracts. White matter tracts shown in the left hemisphere: dorsal cingulum (purple), ventral cingulum, (yellow), SLF 1 (dark green), SLF 2 (red), SLF 3 (sky blue).

Table 1. Cortical areas connected by the SLF

\begin{tabular}{|c|c|c|c|}
\hline \multirow[b]{2}{*}{ Tract } & \multicolumn{3}{|l|}{ Regions of interest for SLF 1-3 } \\
\hline & Frontal region of interest & Parietal region of interest & Exclusion region \\
\hline SLF 1 & Superior frontal gyrus ${ }^{a}$ & Superior parietal gyrus $^{b}+$ precuneus $^{a}$ & Manual exclusion region of interest \\
\hline SLF 3 & $\begin{array}{l}\text { Pars opercularis }{ }^{a}+\text { pars orbitalis }^{a}+ \\
\text { pars triangularis }{ }^{a}\end{array}$ & $\begin{array}{l}\text { Intraparietal sulcus }^{b}+\text { inferior parietal (angular gyrus) }^{a} \\
\quad+\text { supramarginal gyrus }^{a}\end{array}$ & $\begin{array}{l}\text { Manual exclusion } \\
\text { region of interest }\end{array}$ \\
\hline
\end{tabular}

${ }^{a}$ From the Desikan-Killiany Atlas (?h.aparc.annot; Desikan et al., 2006).

${ }^{b}$ From the Destrieux Atlas (?h.aparc.a2009s.annot; Destrieux et al., 2010).

\section{IQD}

To investigate whether functional neuroanatomical compensatory effects could be related to IQ, we assessed the relative dominance of verbal or performance IQ using an IQD index, calculated according to the following formula: IQD $=100 \times[($ verbal IQ - performance IQ $) /($ verbal IQ + performance IQ)].

This index is based on the laterality index that is commonly used in brain imaging studies (Seghier, 2008).

\section{Exploring the association between imaging, behavioral performance, and gestational age}

Due to our hypothesis that damage to the dorsal cingulum may be associated with compensatory activation outside the traditional working memory network, we first correlated cingulum volume (in millimeters cubed) with mean activation (contrast of parameter estimates) in the bilateral region that PBI individuals activated relatively more than controls.

To probe whether this activation was compensatory or detrimental, we then correlated activation in this region and task performance on the threeback condition (which did not suffer the ceiling effects seen in the other conditions), using a $d^{\prime}$ measure. R-to- $z$ transformations were used to statistically compare correlation coefficients (Nieuwenhuis et al., 2011).
As the PBI group had a younger mean gestational age than the VPT-N group, we correlated activation in the same perisylvian region with gestational age at birth across the VPT sample as a whole (VPT-N and PBI groups) to ascertain whether the main findings were principally due to a difference in gestational age rather than PBI. Spearman correlations were used where data were not normally distributed.

\section{Results}

The PBI group had younger gestational age and lower birth weight than the VPT-N group (Table 2). There was a significant difference in performance IQ between the groups, with post hoc tests revealing the $\mathrm{PBI}$ and control groups to be significantly different on this measure $(p=0.006)$ with a trend for lower IQ in the PBI group compared with the VPT-N group $(p=0.065)$.

\section{In-scanner behavioral results}

There were no significant group differences in reaction time in any of the conditions. Reaction time increased in each group with each increase in task difficulty (Table 3 ). 
Table 2. Current and neonatal demographic factors

\begin{tabular}{|c|c|c|c|c|c|}
\hline Demographic variables & $\mathrm{PBI}$ & VPT-N & Controls & Test statistic & Significance \\
\hline Mean age in years $(S D)^{*}$ & $29.94(1.31)$ & $30.23(2.19)$ & $29.94(3.18)$ & $\chi^{2}=0.856$ & $p=0.652$ \\
\hline Gender (female:male)* & $10: 10$ & $10: 11$ & $29: 16$ & $\chi^{2}=2.146$ & $p=0.342$ \\
\hline Mean gestational age in weeks $(S D)^{\wedge}$ & $28.45(2.52)$ & $30.26(1.9)$ & & $W=109.5$ & $p=0.023$ \\
\hline Birth weight in grams (SD)^ & $1203(349)$ & $1502(297)$ & & $t=2.879$ & $p=0.006$ \\
\hline Full scale IQ (SD)* & $105.87(16.94)$ & $108.82(11.77)$ & $115.94(10.44)$ & $F=3.103$ & $p=0.052$ \\
\hline Verbal IQ (SD)* & $109.73(9.6)$ & $105.65(13)$ & $112.5(13.71)$ & $F=1.625$ & $p=0.205$ \\
\hline Performance IQ (SD)* & $98.56(21.1)$ & $110.24(12.11)$ & $115.94(10.44)$ & $F=8.045$ & $p=0.001$ \\
\hline
\end{tabular}

*Three-group comparison.

${ }^{\wedge}$ Two-group comparison (PBI vs VPT-N).

Table 3. Reaction times and accuracy for the $n$-back task

\begin{tabular}{lllll}
\hline & \multicolumn{4}{l}{ Performance on the $n$-back task[mean (SD)] } \\
\cline { 2 - 5 } & Zero-back & One-back & Two-back & Three-back \\
\hline Reaction time (ms) & & & & \\
PBI & $486.05(77.47)$ & $603.19(146.35)$ & $697.23(163.05)$ & $731.18(162.2)$ \\
VPT-N & $518.72(118.69)$ & $601.79(148.05)$ & $690.44(207.92)$ & $750.22(194.62)$ \\
$\quad$ Controls & $508.35(64.82)$ & $574.34(86.05)$ & $648.68(119.96)$ & $723.19(156.64)$ \\
Correct hits (\%) & & & & \\
PBI & $100(0)$ & $96.67(6.35)$ & $84.44(21.45)$ & $69.44(17.61)$ \\
VPT-N & $100(0)$ & $98.94(3.34)$ & $93.12(12.41)$ & $73.02(24.49)$ \\
$\quad$ Controls & $99.52(3.28)$ & $97.83(5.55)$ & $93(12.47)$ & $78.99(12.66)$ \\
\hline
\end{tabular}

Notice the increase in reaction times and the decrease in accuracy for each group as task difficulty increases.

Eighty-four percent of participants performed perfectly (no false-positive and no false-negative errors) on the sensorimotor condition (also known as zero-back), 66\% of participants performed perfectly on the one-back condition, $51 \%$ of participants scored perfectly on the two-back condition, and only $9 \%$ of participants performed perfectly during the three-back condition. As a high number of people scored equally (maximally) on the one-back and two-back conditions, these conditions could not be satisfactorily examined using most statistical tests. In contrast, on the three-back condition, relatively few people scored maximally, creating a wider distribution more amenable to testing. In view of this, we concentrated our analysis on the three-back $d^{\prime}$ values.

A Shapiro-Wilk test showed that the data were not normally distributed $\left(p=2.15 \times 10^{-5}\right)$ and a modified robust BrownForsythe Levene-type test based on absolute deviations from the median showed that group variances were not significantly different $(p=0.73)$.

There was no significant effect of group on three-back $d^{\prime}$ (Kruskal-Wallis $\chi^{2}=2.28, \mathrm{df}=2, p=0.32$; PBI, $2.96 \pm 1.41$; VPT-N, $3.40 \pm 1.42$; control group, $3.42 \pm 1.29)$ or on corrected recognition hits (hit rate minus false-alarm rate) at any level (zero-back: $p=0.754$; one-back: $p=0.211$; two-back: $p=0.071$; three-back: $p=0.09$ ). When one-back, two-back, and three-back trials were pooled together, there were still not significant group differences $\left(\chi^{2}=5.39, p=0.07\right)$.

\section{Functional MRI results}

Between-group results (increasing memory load across all four conditions)

PBI versus controls. The PBI group had lower activation bilaterally in the dorsolateral PFC, the posterior parietal cortex (lateral and medial), the cerebellum, the left dorsomedial PFC, and the ventrolateral PFC when compared with the control group (Fig. 2, hot colors; Table 4). In contrast, the PBI group showed relatively greater activation in bilateral perisylvian clusters encompassing parts of the insula, the superior temporal gyrus, and the subcentral gyrus (Fig. 2, cool colors; Table 4).
PBI versus VPT-N. The PBI group had lower activation in the bilateral cerebellum and the lateral posterior parietal cortex, as well as the left medial posterior parietal cortex, compared with the VPT-N group (Fig. 2, purple; Table 4). These were areas in which the PBI group also exhibited less activation than controls (Fig. 2). In contrast there were no areas in which the PBI group activated more than the VPT-N group.

$V P T-N$ versus controls. There were no significant activation differences between the VPT-N group and controls.

\section{Covarying for sex}

Covarying for sex obtained the same results as those that did not explicitly model sex, with the exception of the cerebellar and ventrolateral PFC clusters from the $\mathrm{PBI}<$ controls contrast, which no longer reached significance.

\section{Analysis of functional activation patterns across working memory difficulty levels}

We then analyzed the activation patterns across working memory difficulty levels in the clusters that significantly differed between the PBI and full-term control groups. The positively and negatively activated clusters were analyzed separately in repeatedmeasures ANOVA analyses, with TaskLevel and BrainRegion as within-subject factors and Group as the between-subject factor.

There was a significant group ${ }^{\star}$ task level interaction in the positively activated frontoparietocerebellar clusters $(F=3.65$, $p=0.007)$ and in the deactivated perisylvian clusters $(F=2.75$, $p=0.030)$.

As a post hoc analysis, we examined the activation trends across groups. In the positively activated regions, there was a linear trend in the PBI group $(F=11.09, p=0.004)$ and a marginal quadratic trend $(F=3.41, p=0.080)$. In the VPT group, there were significant linear and quadratic terms (Linear: $F=$ 23.92, $p<0.001$; Quadratic: $F=8.83, p=0.008$ ) and in the control group there were also significant linear and quadratic terms (Linear: $F=114.25, p<0.001$; Quadratic: $F=32.69, p<$ 0.001).

In the perisylvian regions in the VPT-N and control groups, there was a dominant linear trend (VPT-N: $F=19.23, p<0.001$; control: $F=37.06, p<0.001)$. In the PBI group only a quadratic trend was significant (Linear: $F=2.27, p=0.149$; Quadratic: $F=18.38, p<$ 0.001 ), suggesting an altered pattern of perisylvian activation in the PBI group with increasing cognitive load (Fig. 2).

\section{Tractography results: dorsal cingulum}

There was a significant difference in dorsal cingulum volume across the three groups (ANOVA: $F=4.41$; $\mathrm{df}=2,152 ; p=$ $0.0138)$ in the expanded sample of participants. This remained significant when covarying for $\operatorname{sex}(F=5.90, p=0.003)$. Post hoc comparisons revealed the dorsal cingulum volume to be significantly lower in the PBI group compared with controls $(p=$ 

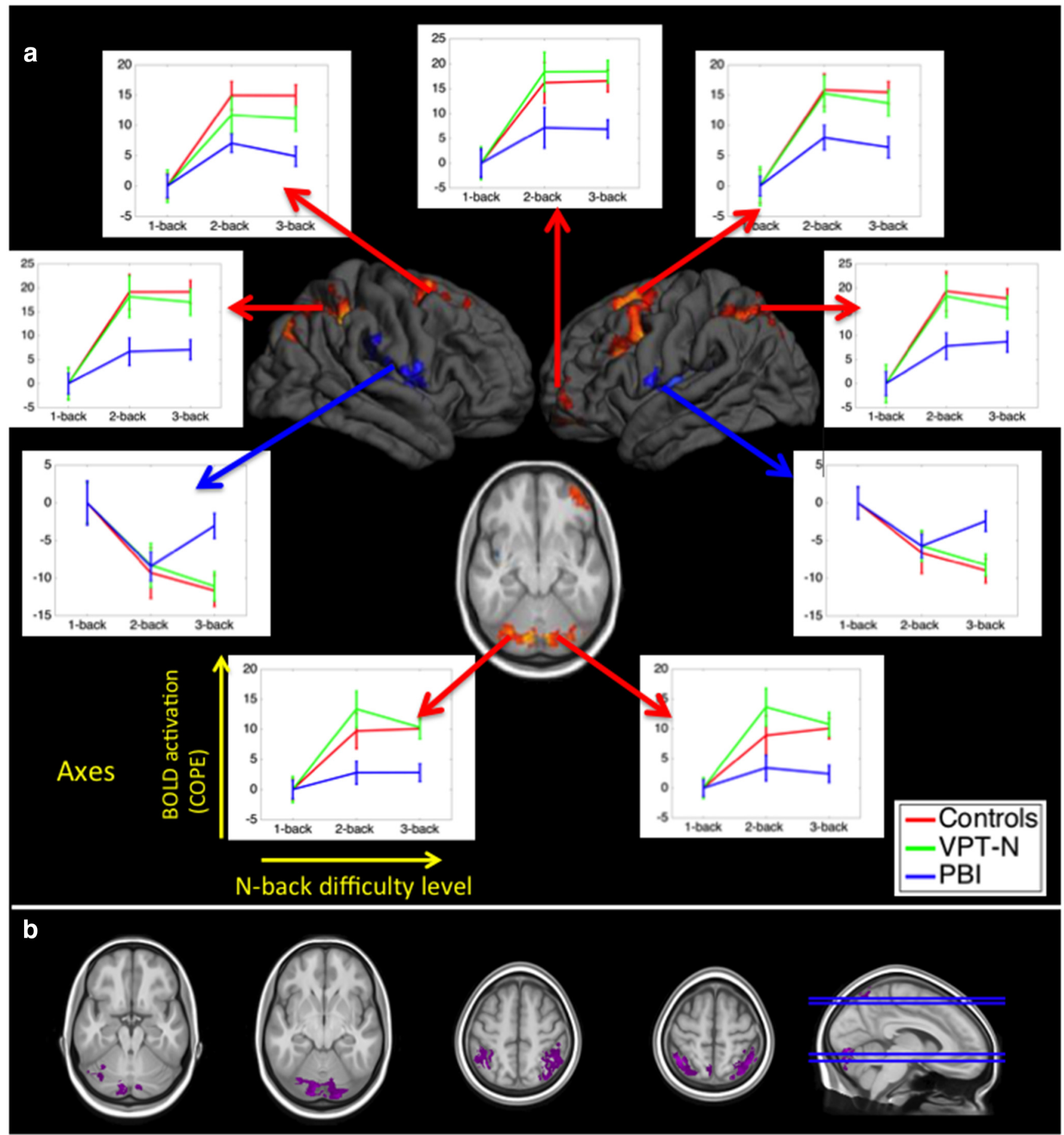

Figure 2. Significant differences in activation across groups during the $n$-back task. $\boldsymbol{a}$, Hot colors represent regions that the PBI group activated less than controls $[p<0.05$, familywise error (FWE) corrected]. Cool colors represent the regions that the PBI group deactivated less than control participants ( $p<0.05$, FWE corrected). No regions were differentially activated between the VPT-N group and controls. Line charts show the mean (SEM) activation for each group in the indicated clusters with increasing cognitive load (using the 1-back condition as a reference to highlight the effects of cognitive load). Note that line charts are shown for illustrative purposes only, and do not constitute formal tests, which were performed using the FSL software. $\boldsymbol{b}$, Differences in activation between the PBI and VPT-N groups reached significance ( $p<0.05$, corrected) in the parietal cortex and cerebellum bilaterally (purple).

$0.004)$ and VPT-N adults $(p=0.038)$. HMOA of the dorsal cingulum was also significantly different between groups $(F=8.94$, $p<0.001)$, and remained significant when covarying for sex $(F=$ 9.34, $p<0.001$ ) with the PBI group having significantly lower HMOA in the dorsal cingulum than the two other groups (PBI vs controls, $p=0.001$; PBI vs VPTN, $p=0.001$; VPTN vs controls, $p=1)$. Note that HMOA $(F=5.79, p=0.004)$ but not volume
$(F=2.06, p=0.134)$ of the dorsal cingulum remains significantly different between groups if the sample is restricted to only those subjects that undertook the fMRI task.

Tractography results: ventral cingulum and SLF 1-3

The dissection of the ventral cingulum and SLF 1-3 as control tracts allowed us to ask the following: (1) whether all tracts likely 
Table 4. Between-group differences in activation during the $n$-back task ( $p<0.05$, FWE-corrected)

\begin{tabular}{|c|c|c|c|c|c|}
\hline BOLD activation between-group contrasts; region & Peak MNI $x$ coordinate $(\mathrm{mm})$ & $Y$ coordinate & $Z$ coordinate & Cluster size (voxels) & Zscore \\
\hline \multicolumn{6}{|l|}{$\mathrm{PBI}>$ Controls } \\
\hline Right perisylvian cortex & 45 & -17 & 0 & 3125 & 3.81 \\
\hline Left perisylvian cortex & -58 & -3 & 2 & 2468 & 3.88 \\
\hline Right parietal cortex & 38 & -63 & 57 & 10,762 & 6.71 \\
\hline Left parietal cortex & -23 & -68 & 59 & 9024 & 6.13 \\
\hline Left dorsal prefrontal & -29 & 8 & 60 & 8617 & 5.56 \\
\hline Left ventrolateral prefrontal & -38 & 54 & 21 & 2807 & 4.27 \\
\hline Left cerebellum & -46 & -71 & 27 & 2456 & 4.24 \\
\hline \multicolumn{6}{|l|}{ VPT-N > PBI } \\
\hline Bilateral cerebellum & -7 & -83 & -16 & 4681 & 4.42 \\
\hline Right parietal cortex & 49 & -50 & 55 & 4481 & 3.88 \\
\hline Left parietal cortex & -39 & -62 & 57 & 3187 & 4.43 \\
\hline
\end{tabular}

Note that analysis was carried out in the space of the study-specific template. Results were mapped from the custom template into MNI space in order to allow for co-ordinates to be reported. There were no significant clusters in the PBI $>$ VPT-N, Controls > VPT-N, and VPT-N > Controls contrasts.

to be affected by PBI are associated with reorganization of the working memory network, even if they are not central to working memory function (ventral cingulum) and (2) whether all working memory-related tracts are affected by PBI, even if they are distant from the lateral ventricles (SLF 1-3).

There was a significant difference in volume of the ventral cingulum across the three groups (ANOVA: $F=3.74$; $\mathrm{df}=2,152$; $p=0.026)$, which remained when covarying for sex $(F=4.39$, $p=0.014)$. Post hoc comparisons revealed the ventral cingulum volume to be significantly lower in the PBI group compared with controls $(p=0.029)$. There were no significant between-group differences in HMOA of the ventral cingulum $\left(\chi^{2}=2.25, p=\right.$ $0.326)$

SLF 1 and SLF 3 volume did not significantly differ between the groups $\left(\chi^{2}=1.33, p=0.515 ; \chi^{2}=5.01, p=0.082\right)$, even when covarying for $\operatorname{sex}(F=1.45, p=0.238 ; F=1.84, p=0.163)$. A Kruskall-Wallis test showed a significant difference in the volume of the SLF 2 across the three groups, with controls having the lowest volume, although Bonferroni's post hoc tests did not reveal significant differences between the groups (PBI vs controls, corrected $p=0.180$; VPTN vs controls, corrected $p=0.108$; PBI vs VPTN, corrected $p=1$ ); these results were no longer significant after adjusting for $\operatorname{sex}(F=2.52, p=0.084)$. There were no between-group differences in HMOA of the SLF $1(F=2.26, p=$ 0.108 ; or when adjusting for sex: $F=2.33, p=0.101)$ or SLF $2\left(\chi^{2}\right.$ $=2.99, p=0.225$; or when adjusting for sex: $F=1.586, p=$ $0.208)$. There was a significant difference in HMOA of the SLF 3 $\left(\chi^{2}=11.57, p=0.003\right.$; or when adjusting for sex: $F=5.52, p=$ $0.005)$, with the control group having lower HMOA than the two other groups (PBI vs control, $p=0.006$; VPTN vs control, $p=$ 0.032; PBI vs VPTN, $p=0.504)$.

\section{Correlation between structure and function}

We investigated whether activation in the perisylvian region, where the PBI group showed increased activation compared with controls, was related to neonatal injury to the dorsal cingulum tract, which connects key medial frontoparietal working memory structures (Fig. 3).

There was a significant negative correlation between dorsal cingulum volume and perisylvian activation in the PBI group $(r=-0.49, p=0.030)$. Dorsal cingulum volume was not correlated with perisylvian activation in the VPT-N $(r=0.07, p=1)$ or control groups $(r=0.06, p=1)$. The dorsal cingulum-perisyl- vian activation correlation was significantly different in the PBI group from that seen in the VPT-N $(z=-1.75, p=0.040$ onetailed) and control groups $(z=-2.06, p=0.020$ one-tailed). Furthermore, the structure-function correlation was statistically significant only at the highest cognitive load of the $n$-back task when contrasting the three levels of working memory difficulty with baseline (one-back: $r=-0.10, p=0.682$; two-back: $r=$ $-0.23, p=0.332$; three-back: $r=-0.49, p=0.030)$. HMOA did not significantly correlate with perisylvian activation in any group (all $p>0.2$ ).

On the contrary, there was no significant correlation between the volume of the ventral cingulum and perisylvian activation in the PBI group $(r=0.17, p=0.486)$ or in either of the other two groups (VPT-N: $r=0.04, p=0.870$; controls: $r=0.06, p=$ $0.706)$. Furthermore, there was no statistically significant correlation between the volume of SLF 1, 2, or 3 and perisylvian activation in any group (all $p>0.14$ ).

\section{Functional activation and task performance}

To test whether the relative hyperactivation of the perisylvian area in the PBI group was associated with on-line task performance, we correlated activation in these clusters with performance on the hardest working memory condition (three-back) in the PBI group and found that activation positively correlated with performance $(r=0.57, p=0.009)$. There was no significant relationship between task performance and perisylvian activation in the VPT-N $(r=-0.27, p=0.24)$ or control $(r=0.05, p=$ $0.74)$ groups. Furthermore, this activation-behavior correlation was significantly stronger in the PBI group compared with each of the other two groups (PBI vs VPTN: $z=2.72, p=0.007$; PBI vs controls: $z=2.07, p=0.039$; Fig. 4 ).

To further probe the relationship between working memory load, task performance, and activation, we assessed in an exploratory post hoc analysis the relationship between the change in activation in the perisylvian cortex from the two-back to the three-back condition (i.e., where the PBI group showed the most marked differences compared with the VPT-N and control groups; Fig. 2) and task performance (three-back $d^{\prime}$ ), while controlling for any minor between-group differences in activation from one-back to two-back. The increase in activity from the moderately hard two-back to the very hard three-back condition in the PBI group was associated with increased task performance 


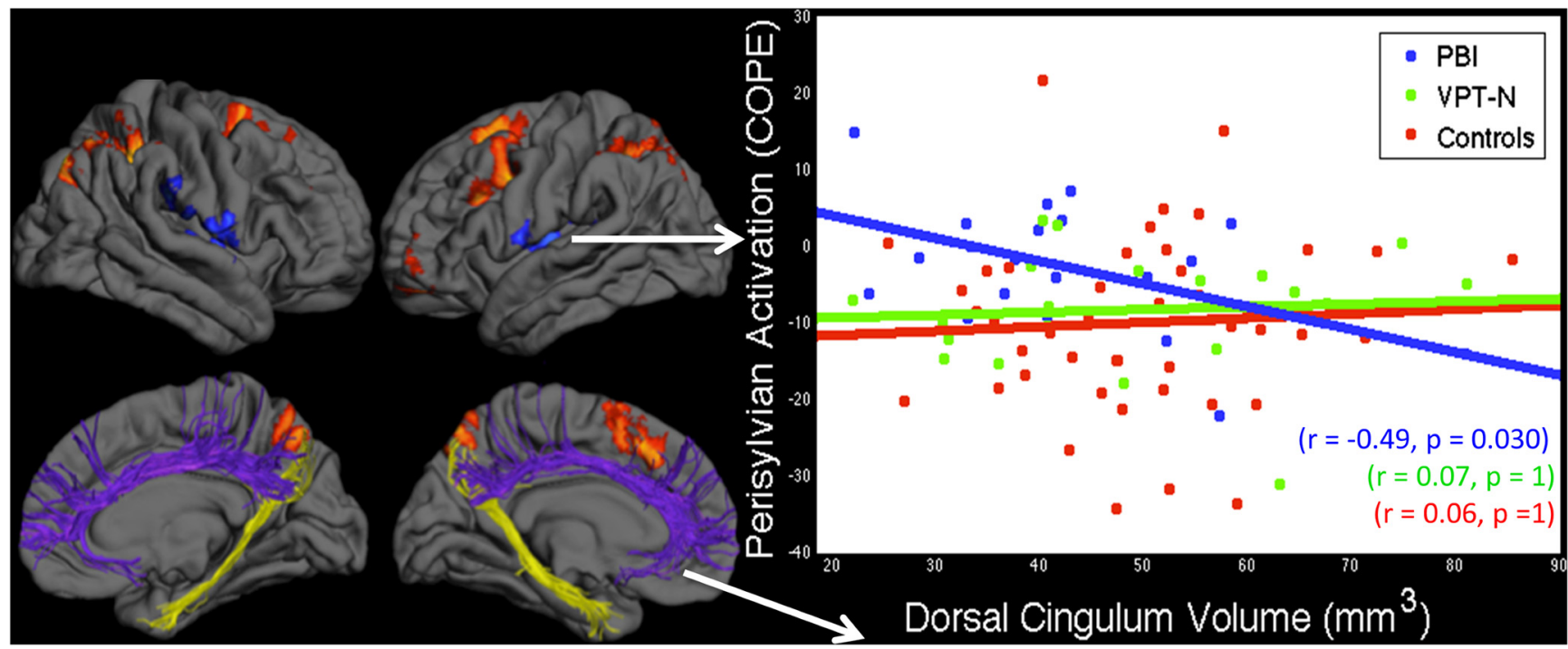

Figure 3. Structure-function relationships. The volume of the dorsal cingulum bundle (purple), which connects key medial frontal and parietal nodes of the working memory network (hot colors) is inversely correlated with compensatory activation of the perisylvian cortex (cool colors) in the PBI group (right, blue) but not in the VPT-N or control groups (right; green, red respectively). This was not a general effect of white matter damage in the PBI group as no such correlation was observed between activation in the perisylvian cortex and the volume of the ventral cingulum (yellow; $r=$ $0.165, p=0.760$ ), which connects medial temporal and parietal lobe structures and is thought to be involved in episodic memory.

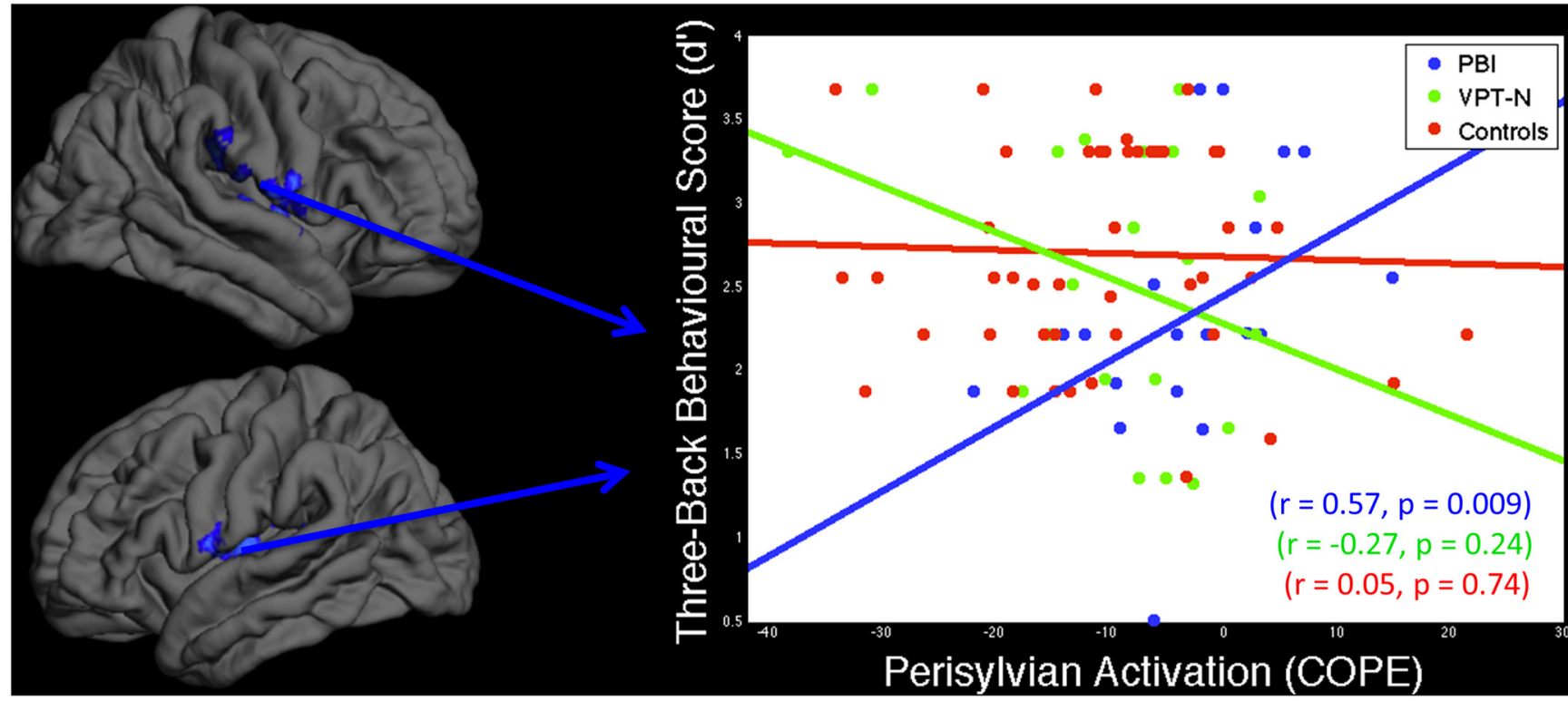

Figure 4. Compensatory activation of perisylvian cortex. Activation in perisylvian cortex positively correlated with working memory performance in the PBI (blue), but not in VPT-N or control groups (green and red, respectively). Least-squared lines are shown for illustrative purposes only and do not constitute a formal test. Spearman correlations were performed to test for brainbehavior relationships.

$(r=0.46, p=0.047)$, while no significant relationship was found in the VPTN $(r=-0.35, p=0.134)$ or full-term control groups $(r=-0.05, p=0.746)$.

No significant relationship between task performance (threeback $d^{\prime}$ ) and frontoparietocerebellar activation was detected in any of the three groups (PBI: $r=0.29, p=0.212$; VPT-N: $r=$ $0.14, p=0.548$; controls: $r=0.04, p=0.779)$.

Functional activation and gestational age at birth

Gestational age in all participants born very preterm was not significantly correlated with BOLD activation in the perisylvian area $(r=0.165, p=0.314)$.
Ventricular volumes

Ventricular volumes (as a proportion of intracranial volume) differed significantly between groups in both the original fMRI sample $\left(\chi^{2}=20.225, p<0.001\right)$ and the expanded diffusion MRI (dMRI) sample $\left(\chi^{2}=29.393, p<0.001\right)$, with the PBI group having the largest ventricles (fMRI sample: $30,355 \pm 27,408$ $\mathrm{mm}^{3}$; dMRI sample: $30,237 \pm 28,717 \mathrm{~mm}^{3}$ ), followed by the VPTN group (fMRI sample: $17,303 \pm 7264 \mathrm{~mm}^{3}$; dMRI sample: $16,699 \pm 8634 \mathrm{~mm}^{3}$ ) and the control group (fMRI sample: 10,821 $\pm 4976 \mathrm{~mm}^{3}$; dMRI sample: 11,496 $\pm 6135 \mathrm{~mm}^{3}$ ). Post hoc Mann-Whitney $U$ tests revealed significant differences in ventricle volume between each of the three groups (PBI vs VPTN, 
corrected $p=0.02 ; \mathrm{PBI}$ vs control, corrected $p=0.001$; VPTN vs control, corrected $p=0.003$ ).

\section{Effects of sex}

The critical outcome variables-perisylvian activation, dorsal cingulum volume, and three-back $d^{\prime}$ score-were then analyzed with respect to sex effects. Three full factorial models were created, each with sex and group as fixed factors and perisylvian activation, dorsal cingulum volume, or three-back $d^{\prime}$ as dependent variables.

In the first model, with perisylvian activation as the dependent variable, there was a significant effect of group $(F=4.197, p=$ $0.018)$ and a significant effect of $\operatorname{sex}(F=6.694, p=0.011$, with greater deactivation in males) but no group ${ }^{*}$ sex interaction $(F=$ $0.845, p=0.433$ ), signifying that group had a significant effect on perisylvian activation independent of sex.

In the second model, with dorsal cingulum volume as the dependent variable, there was a significant effect of group $(F=$ $5.739, p=0.004)$, sex $(F=22.805, p<0.001$, with greater dorsal cingulum volume in males), but no group ${ }^{*}$ sex interaction $(F=$ $0.400, p=0.671$ ), signifying that group had a significant effect on dorsal cingulum volume independent of sex.

In the third model, with three-back $d^{\prime}$ as the dependent variable, there was no significant effect of group $(F=1.573, p=$ $0.214), \operatorname{sex}(F=0.018, p=0.895)$, or group ${ }^{\star} \operatorname{sex}$ interaction $(F=$ $0.335, p=0.716)$.

\section{IQD}

As shown in Table 2, the PBI group demonstrated a greater difference between verbal and performance IQ than the other study groups.

IQD significantly differed between the groups $(F=7.192, p=$ 0.002 ), with the PBI having significantly higher IQD (i.e., higher verbal/performance IQ ratio) compared with the two other groups (PBI vs controls, $p=0.002$; PBI vs VPT-N, $p=0.007$; VPT-N vs controls, $p=1$ ). However, IQD did not correlate significantly with three-back $d^{\prime}$ in any group (all $p>0.6$ ). In the control group, a significant negative correlation was detected between IQD and perisylvian activation $(r=0.508, p=0.003)$, indicating that greater verbal IQD was associated with greater deactivation of the perisylvian cortex with increasing cognitive demand. This relationship was not found in the other two groups (VPT-N: $r=0.335, p=0.161$; PBI: $r=-0.082, p=0.771$ ).

\section{Discussion}

In this study we investigated the brain's means of compensating for alterations to the working memory network associated with PBI. The PBI group had relatively preserved working memory performance, apparently supported by compensatory activity in the perisylvian cortex, despite reduced activation in typical frontoparietal working memory areas and smaller volume of the dorsal cingulum.

Previous work found increased gray matter volume in adolescents with PBI in frontal and medial parietal cortex, possibly reflecting delayed or incomplete anatomical maturation of these structures (e.g., by synaptic pruning; Nosarti et al., 2008). The dorsal cingulum connects these medial working memory structures and lies superior to the corpus callosum and lateral ventricles, making it vulnerable to PBI. Alterations to the dorsal cingulum exist in adolescents born VPT (Eikenes et al., 2011), and such alterations can impair working memory function (Winston et al., 2013). We found reduced dorsal cingulum volume in the PBI group compared with controls, which was negatively correlated with perisylvian activation in the PBI group, but not the VPT-N or control groups, suggesting a structure-function relationship that is uniquely present following PBI. Furthermore, we show that, among the tracts we studied, only the dorsal cingulum is associated with functional alterations in the perisylvian cortex.

This may be explained by the dorsal cingulum being unique among the tracts studied in both (1) being at high risk of perinatal periventricular injury (like the ventral cingulum, but not the SLF) and (2) connecting working memory regions (like the SLF, but not the ventral cingulum).

We hypothesized that, in the PBI group, increased activation outside the frontoparietal network would be compensatory. An alternative hypothesis is that activation increases in the PBI group relative to controls would be maladaptive and hinder task completion (Myers et al., 2010). To test these competing hypotheses, we correlated perisylvian activation with working memory performance. We found that less inhibition of perisylvian regions correlated with improved task performance, and that this relationship was unique to the PBI group, suggesting a novel compensatory process had developed in this group. Indeed, the less the PBI group resembled controls (in perisylvian activation), the better they performed.

Reduced cerebellar activation was also found in the PBI group, although this was no longer statistically significant when sex was included in the model as a covariate of no interest. Several studies have suggested a role for the cerebellum in working memory (Desmond et al., 1997; Ravizza et al., 2006; Boehringer et al., 2013; Blokland et al., 2014). The cerebellum likely connects to cortical regions of the working memory network through direct frontocerebellar tracts and indirect routes via the pons and thalamus (Ramnani et al., 2006; Salmi et al., 2010). Structural and functional alterations of the cerebellum are common following VPT birth (Parker et al., 2008; Lawrence et al., 2014) and are associated with worse neurodevelopmental and neuropsychological outcome (Messerschmidt et al., 2008; Parker et al., 2008). Furthermore, the cerebellum is particularly vulnerable to PBI, even in modern VPT cohorts (Limperopoulos et al., 2005). Therefore, alterations to the cerebellum or its connections may affect working memory function in adulthood following PBI.

The PBI group also differed from the VPT-N group in cerebellar and parietal activation. Differences in frontal and perisylvian activation were not statistically significant, possibly due to the small sample size, or shared developmental factors between the VPT groups leading to alterations of the working memory system. The activation pattern in the VPT-N group was more similar to that seen in the control group, however, and no functional, structural, or behavioral differences were found between these two groups. While this is striking in the context of an extensive literature documenting working memory problems following preterm birth (Luciana et al., 1999; Böhm et al., 2004; Sansavini et al., 2007; Mulder et al., 2010), strong conclusions about working memory ability in this group should not be made without a more comprehensive working memory assessment.

Although previous studies have found a significant relationship between SLF microstructure and working memory function (Østby et al., 2011; Vestergaard et al., 2011), we did not find an association, possibly due to the working memory assessment used. While the PBI group had reduced volume and HMOA of the dorsal cingulum compared with controls, they had increased HMOA in the SLF 3. These results suggest the possibility of lateral neuroanatomical compensation for medial structural deficits in the PBI group, a hypothesis we will investigate further in future studies. 
Previous investigations of the SLF in preterm children (Murray et al., 2015) and adolescents (Frye et al., 2010) failed to detect microstructural alterations. These studies relied on diffusion tensor imaging measures, such as FA, and included tracts projecting to the temporal lobe (also known as the arcuate fasciculus; Catani and Thiebaut de Schotten, 2008; Thiebaut de Schotten et al., 2011). Simulations suggest that HMOA may be a more sensitive measure than FA, and is more appropriate for tracts that are highly affected by crossing fibers, such as the SLF, as it does not average across all tracts within a voxel (Dell'Acqua et al., 2013). It would be interesting to see whether such alterations could be detected in younger cohorts with available spherical deconvolution data (Murray et al., 2015) to distinguish methodological from developmental differences.

The areas showing less inhibition of activation in the PBI group included areas related to verbal repetition, such as the posterior insula, subcentral gyrus, and superior temporal gyrus (Koelsch et al., 2009; Cloutman et al., 2012), perhaps suggesting a means by which perisylvian activation could aid working memory function in this group. We noted a negative correlation between IQD and perisylvian activation in the control group but not the PBI group, perhaps suggesting an altered role of the perisylvian cortex in these individuals.

In contrast with previous studies in children and adolescents showing lasting effects of PBI on working memory function (Woodward et al., 2005; Beauchamp et al., 2008; Anderson et al., 2010), and evidence from animal models suggesting longer-term dysfunction (Chambers et al., 1996; Lipska et al., 2002; Arteni et al., 2003), we found no significant working memory performance differences between groups. This finding is in line with a recent case study of a patient with severe PBI that found no evidence of working memory impairment at 28 years of age (Baddeley et al., 2010) and an fMRI study of working memory in adults born VPT that found no performance differences on the two-back working memory task (Daamen et al., 2015), suggesting that catch-up in working memory function may continue into adulthood (Nosarti and Froudist-Walsh, 2015).

Daamen and colleagues found altered deactivation of the medial parietal cortex and cerebellum in adults born VPT (Daamen et al., 2015). They suggested that this could be a compensatory alteration, although activation patterns did not correlate with task performance. In contrast to the present study, individuals born VPT with and without PBI were not studied separately. This choice may have masked activation differences that were attributable primarily to individuals with PBI. Furthermore, in the current study, differences in perisylvian activation in the PBI group were only noted in the hardest working memory condition (three-back), which was not assessed by Daamen et al. In contrast, the increased power afforded by the larger heterogeneous preterm group in that study may have enabled Daamen and colleagues to detect altered deactivation patterns that we were unable to observe here.

Our results point to adults with PBI upregulating activity in the perisylvian cortex as a means to compensate for reduced working memory capacity. Promotion of such compensatory activity in PBI individuals may be a manner in which neuroscientific information could inform the development of cognitive interventions (Berthier and Pulvermüller, 2011; Pascoe et al., 2013). Further work is required to identify the periods in which the brain's functional networks undergo major changes following PBI. This information may help identify the age at which working memory interventions designed to improve academic functioning may be most effective (Wass et al., 2012; Pascoe et al., 2013).
A limitation of this study is the lack of an independent test of working memory ability, which would have allowed for further validation of the brain-behavior relationships. There were significant differences in birth weight and gestational age between the PBI and VPT-N groups. While gestational age was not significantly correlated with perisylvian activation, we cannot exclude the possibility that these results could in part relate to extreme prematurity. We used ultrasound, which does not have the sensitivity or specificity of neonatal MRI, to diagnose PBI. Nonetheless, the PBI group still had larger lateral ventricles at current assessment, suggesting long-term neuroanatomical sequelae to perinatal periventricular damage. The VPT-N group had intermediate ventricle size, indicating the possibility of residual brain injury that was not detected on neonatal ultrasound.

We used a hypothesis-driven approach and found significant associations between dorsal cingulum volume and perisylvian activation in the PBI group. On the other hand, the use of a data-driven approach, such as fMRI-informed tractography (i.e., using functional areas as a seed region; Salvan et al., 2014), may have shed light on how the perisylvian cortex connects with the rest of the working memory system.

To our knowledge, this is the first multimodal imaging study to investigate the functional and structural correlates of adult working memory following PBI. We found minimal differences in working memory performance between controls and individuals with a history of VPT birth or PBI. We did, however, detect large reductions in functional activation in typical frontoparietocerebellar regions of the working memory network in PBI young adults. This underutilization of traditional working memory resources was accompanied by reduced volume of the dorsal cingulum tract and was offset by the beneficial upregulation of activation in perisylvian cortex. These results add to our understanding of the developmental trajectories of cognitive abilities following VPT birth and perinatal brain injury and shed new light on the mechanisms the brain develops to compensate for early cognitive and anatomical deficits.

\section{References}

Anderson V, Spencer-Smith M, Coleman L, Anderson P, Williams J, Greenham M, Leventer RJ, Jacobs R (2010) Children's executive functions: are they poorer after very early brain insult. Neuropsychologia 48:2041-2050. CrossRef Medline

Arteni NS, Salgueiro J, Torres I, Achaval M, Netto CA (2003) Neonatal cerebral hypoxia-ischemia causes lateralized memory impairments in the adult rat. Brain Res 973:171-178. CrossRef Medline

Avants BB, Yushkevich P, Pluta J, Minkoff D, Korczykowski M, Detre J, Gee JC (2010) The optimal template effect in hippocampus studies of diseased populations. Neuroimage 49:2457-2466. CrossRef Medline

Avants BB, Tustison NJ, Song G, Cook PA, Klein A, Gee JC (2011) A reproducible evaluation of ANTs similarity metric performance in brain image registration. Neuroimage 54:2033-2044. CrossRef Medline

Baddeley A (2003) Working memory: looking back and looking forward. Nat Rev Neurosci 4:829-839. CrossRef Medline

Baddeley A, Allen R, Vargha-Khadem F (2010) Is the hippocampus necessary for visual and verbal binding in working memory? Neuropsychologia 48:1089-1095. CrossRef Medline

Ballabh P (2014) Pathogenesis and prevention of intraventricular hemorrhage. Clin Perinatol 41:47-67. CrossRef Medline

Beauchamp MH, Thompson DK, Howard K, Doyle LW, Egan GF, Inder TE, Anderson PJ (2008) Preterm infant hippocampal volumes correlate with later working memory deficits. Brain 131:2986-2994. CrossRef Medline

Beckmann CF (2004) Probabilistic ICA for FMRI. IEEE International Symposium on Biomedical Imaging: Macro to Nano. pp 1490-1493. CrossRef

Berthier ML, Pulvermüller F (2011) Neuroscience insights improve neurorehabilitation of poststroke aphasia. Nat Rev Neurol 7:86-97. CrossRef Medline 
Blokland GA, McMahon KL, Thompson PM, Hickie IB, Martin NG, de Zubicaray GI, Wright MJ (2014) Genetic effects on the cerebellar role in working memory: same brain, different genes? Neuroimage 86:392-403. CrossRef Medline

Boehringer A, Macher K, Dukart J, Villringer A, Pleger B (2013) Cerebellar transcranial direct current stimulation modulates verbal working memory. Brain Stimul 6:649-653. CrossRef Medline

Böhm B, Smedler AC, Forssberg H (2004) Impulse control, working memory and other executive functions in preterm children when starting school. Acta Paediatr 93:1363-1371. CrossRef Medline

Catani M, Thiebaut de Schotten M (2008) A diffusion tensor imaging tractography atlas for virtual in vivo dissections. Cortex 44:1105-1132. CrossRef Medline

Chambers RA, Moore J, McEvoy JP, Levin ED (1996) Cognitive effects of neonatal hippocampal lesions in a rat model of schizophrenia. Neuropsychopharmacology 15:587-594. CrossRef Medline

Cloutman LL, Binney RJ, Drakesmith M, Parker GJ, Lambon Ralph MA (2012) The variation of function across the human insula mirrors its patterns of structural connectivity: evidence from in vivo probabilistic tractography. Neuroimage 59:3514-3521. CrossRef Medline

Daamen M, Bäuml JG, Scheef L, Sorg C, Busch B, Baumann N, Bartmann P, Wolke D, Wohlschläger A, Boecker H (2015) Working memory in preterm-born adults: load-dependent compensatory activity of the posterior default mode network. Hum Brain Mapp 36:1121-1137. CrossRef Medline

Dale AM, Fischl B, Sereno MI (1999) Cortical surface-based analysis-I. Segmentation and surface reconstruction. Neuroimage 9:179-194. CrossRef Medline

Dell'acqua F, Scifo P, Rizzo G, Catani M, Simmons A, Scotti G, Fazio F (2010) A modified damped Richardson-Lucy algorithm to reduce isotropic background effects in spherical deconvolution. Neuroimage 49:14461458. CrossRef Medline

Dell'Acqua F, Simmons A, Williams SC, Catani M (2013) Can spherical deconvolution provide more information than fiber orientations? Hindrance modulated orientational anisotropy, a true-tract specific index to characterize white matter diffusion. Hum Brain Mapp 34:2464-2483. CrossRef Medline

Desikan RS, Ségonne F, Fischl B, Quinn BT, Dickerson BC, Blacker D, Buckner RL, Dale AM, Maguire RP, Hyman BT, Albert MS, Killiany RJ (2006) An automated labeling system for subdividing the human cerebral cortex on MRI scans into gyral based regions of interest. Neuroimage 31:968980. CrossRef Medline

Desmond JE, Gabrieli JD, Wagner AD, Ginier BL, Glover GH (1997) Lobular patterns of cerebellar activation in verbal working-memory and finger-tapping tasks as revealed by functional MRI. J Neurosci 17:96759685. Medline

Destrieux C, Fischl B, Dale A, Halgren E (2010) Automatic parcellation of human cortical gyri and sulci using standard anatomical nomenclature. Neuroimage 53:1-15. CrossRef Medline

Doria V, Beckmann CF, Arichi T, Merchant N, Groppo M, Turkheimer FE, Counsell SJ, Murgasova M, Aljabar P, Nunes RG, Larkman DJ, Rees G, Edwards AD (2010) Emergence of resting state networks in the preterm human brain. Proc Natl Acad Sci U S A 107:20015-20020. CrossRef Medline

Eikenes L, Løhaugen GC, Brubakk AM, Skranes J, Håberg AK (2011) Young adults born preterm with very low birth weight demonstrate widespread white matter alterations on brain DTI. Neuroimage 54:1774-1785. CrossRef Medline

Fischl B (2012) FreeSurfer. Neuroimage 62:774-781. CrossRef Medline

Fischl B, Liu A, Dale AM (2001) Automated manifold surgery: constructing geometrically accurate and topologically correct models of the human cerebral cortex. IEEE Trans Med Imaging 20:70-80. CrossRef Medline

Fischl B, Salat DH, Busa E, Albert M, Dieterich M, Haselgrove C, van der Kouwe A, Killiany R, Kennedy D, Klaveness S, Montillo A, Makris N, Rosen B, Dale AM (2002) Whole brain segmentation: automated labeling of neuroanatomical structures in the human brain. Neuron 33:341355. CrossRef Medline

Fischl B, van der Kouwe A, Destrieux C, Halgren E, Ségonne F, Salat DH, Busa E, Seidman LJ, Goldstein J, Kennedy D, Caviness V, Makris N, Rosen B, Dale AM (2004) Automatically parcellating the human cerebral cortex. Cereb Cortex 14:11-22. CrossRef Medline

Frye RE, Hasan K, Malmberg B, Desouza L, Swank P, Smith K, Landry S (2010) Superior longitudinal fasciculus and cognitive dysfunction in ad- olescents born preterm and at term. Dev Med Child Neurol 52:760-766. CrossRef Medline

Greve DN, Fischl B (2009) Accurate and robust brain image alignment using boundary-based registration. Neuroimage 48:63-72. CrossRef Medline

Haatveit BC, Sundet K, Hugdahl K, Ueland T, Melle I, Andreassen OA (2010) The validity of $d$ prime as a working memory index: results from the "Bergen n-back task". J Clin Exp Neuropsychol 32:871-880. CrossRef Medline

Hensch TK (2004) Critical period regulation. Annu Rev Neurosci 27:549_ 579. CrossRef Medline

Jenkinson M, Bannister P, Brady M, Smith S (2002) Improved optimization for the robust and accurate linear registration and motion correction of brain images. Neuroimage 17:825-841. CrossRef Medline

Jenkinson M, Beckmann CF, Behrens TE, Woolrich MW, Smith SM (2012) Fsl. Neuroimage 62:782-790. CrossRef Medline

Jeurissen B, Leemans A, Tournier JD, Jones DK, Sjibers J (2013) Investigating the prevalence of complex fiber configurations in white matter tissue with diffusion magnetic resonance imaging. Hum Brain Mapp 34:2747-2766. CrossRef Medline

Just MA, Varma S (2007) The organization of thinking: what functional brain imaging reveals about the neuroarchitecture of complex cognition. Cogn Affect Behav Neurosci 7:153-191. CrossRef Medline

Kane MJ, Brown LH, McVay JC, Silvia PJ, Myin-Germeys I, Kwapil TR (2007) For whom the mind wanders, and when: an experience-sampling study of working memory and executive control in daily life. Psychol Sci 18:614-621. CrossRef Medline

Kelly RE Jr, Alexopoulos GS, Wang Z, Gunning FM, Murphy CF, Morimoto SS, Kanellopoulos D, Jia Z, Lim KO, Hoptman MJ (2010) Visual inspection of independent components: defining a procedure for artifact removal from fMRI data. J Neurosci Methods 189:233-245. CrossRef Medline

Kleim JA, Jones TA (2008) Principles of experience-dependent neural plasticity: implications for rehabilitation after brain damage. J Speech Lang Hear Res 51:S225-S239. CrossRef Medline

Klein A, Andersson J, Ardekani BA, Ashburner J, Avants B, Chiang MC, Christensen GE, Collins DL, Gee J, Hellier P, Song JH, Jenkinson M, Lepage C, Rueckert D, Thompson P, Vercauteren T, Woods RP, Mann JJ, Parsey RV (2009) Evaluation of 14 nonlinear deformation algorithms applied to human brain MRI registration. Neuroimage 46:786-802. CrossRef Medline

Koelsch S, Schulze K, Sammler D, Fritz T, Müller K, Gruber O (2009) Functional architecture of verbal and tonal working memory: an fMRI study. Hum Brain Mapp 30:859-873. CrossRef Medline

Lawrence EJ, Froudist-Walsh S, Neilan R, Nam KW, Giampietro V, McGuire P, Murray RM, Nosarti C (2014) Motor fMRI and cortical grey matter volume in adults born very preterm. Dev Cogn Neurosci 10:1-9. CrossRef Medline

Leemans A, Jeurissen B, Sijbers J, Jones DK (2009) ExploreDTI: a graphical toolbox for processing, analyzing, and visualizing diffusion MR data. $\mathrm{Pa}-$ per presented at $17^{\text {th }}$ Annual Meeting of International Society of Magnetic Resonance in Medicine, Honolulu, HI.

Levene MI (1981) Measurement of the growth of the lateral ventricles in preterm infants with real-time ultrasound. Arch Dis Child 56:900-904. Medline

Limperopoulos C, Benson CB, Bassan H, Disalvo DN, Kinnamon DD, Moore M, Ringer SA, Volpe JJ, du Plessis AJ (2005) Cerebellar hemorrhage in the preterm infant: ultrasonographic findings and risk factors. Pediatrics 116:717-724. CrossRef Medline

Lipska BK, Aultman JM, Verma A, Weinberger DR, Moghaddam B (2002) Neonatal damage of the ventral hippocampus impairs working memory in the rat. Neuropsychopharmacology 27:47-54. CrossRef Medline

Luciana M, Lindeke L, Georgieff M, Mills M, Nelson CA (1999) Neurobehavioral evidence for working-memory deficits in school-aged children with histories of prematurity. Dev Med Child Neurol 41:521-533. CrossRef Medline

Luu TM, Ment LR, Schneider KC, Katz KH, Allan WC, Vohr BR (2009) Lasting effects of preterm birth and neonatal brain hemorrhage at 12 years of age. Pediatrics 123:1037-1044. CrossRef Medline

Marcus DS, Harms MP, Snyder AZ, Jenkinson M, Wilson JA, Glasser MF, Barch DM, Archie KA, Burgess GC, Ramaratnam M, Hodge M, Horton W, Herrick R, Olsen T, McKay M, House M, Hileman M, Reid E, Harwell J, Coalson T, et al. (2013) Human Connectome Project informatics: quality control, database services, and data visualization. Neuroimage 80:202-219. CrossRef Medline 
McCrea HJ, Ment LR (2008) The diagnosis, management, and postnatal prevention of intraventricular hemorrhage in the preterm neonate. Clin Perinatol 35:777-792, vii. CrossRef Medline

Messerschmidt A, Fuiko R, Prayer D, Brugger PC, Boltshauser E, Zoder G, Sterniste W, Weber M, Birnbacher R (2008) Disrupted cerebellar development in preterm infants is associated with impaired neurodevelopmental outcome. Eur J Pediatr 167:1141-1147. CrossRef Medline

Minka T (2000) Automatic choice of dimensionality for PCA. In: Technical report 514. Cambridge, MA: MIT Media Lab Vision and Modeling Group.

Mulder H, Pitchford NJ, Marlow N (2010) Processing speed and working memory underlie academic attainment in very preterm children. Arch Dis Child Fetal Neonatal Ed 95:F267-F272. CrossRef Medline

Murray AL, Thompson DK, Pascoe L, Leemans A, Inder TE, Doyle LW, Anderson JF, Anderson PJ (2015) White matter abnormalities and impaired attention abilities in children born very preterm. Neuroimage 124: 75-84. CrossRef Medline

Myers EH, Hampson M, Vohr B, Lacadie C, Frost SJ, Pugh KR, Katz KH, Schneider KC, Makuch RW, Constable RT, Ment LR (2010) Functional connectivity to a right hemisphere language center in prematurely born adolescents. Neuroimage 51:1445-1452. CrossRef Medline

Nieuwenhuis S, Forstmann BU, Wagenmakers EJ (2011) Erroneous analyses of interactions in neuroscience: a problem of significance. Nat Neurosci 14:1105-1107. CrossRef Medline

Nosarti C, Froudist-Walsh S (2015) Alterations in development of hippocampal and cortical memory mechanisms following very preterm birth. Dev Med Child Neurol, in press.

Nosarti C, Giouroukou E, Healy E, Rifkin L, Walshe M, Reichenberg A, Chitnis X, Williams SC, Murray RM (2008) Grey and white matter distribution in very preterm adolescents mediates neurodevelopmental outcome. Brain 131:205-217. Medline

Østby Y, Tamnes CK, Fjell AM, Walhovd KB (2011) Morphometry and connectivity of the fronto-parietal verbal working memory network in development. Neuropsychologia 49:3854-3862. CrossRef Medline

Owen AM, McMillan KM, Laird AR, Bullmore E (2005) N-back working memory paradigm: a meta-analysis of normative functional neuroimaging studies. Hum Brain Mapp 25:46-59. CrossRef Medline

Parker J, Mitchell A, Kalpakidou A, Walshe M, Jung HY, Nosarti C, Santosh P, Rifkin L, Wyatt J, Murray RM, Allin M (2008) Cerebellar growth and behavioural and neuropsychological outcome in preterm adolescents. Brain 131:1344-1351. Medline

Pascoe L, Roberts G, Doyle LW, Lee KJ, Thompson DK, Seal ML, Josev EK, Nosarti C, Gathercole S, Anderson PJ (2013) Preventing academic difficulties in preterm children: a randomised controlled trial of an adaptive working memory training intervention-IMPRINT study. BMC Pediatr 13:144. CrossRef Medline

Patenaude B, Smith SM, Kennedy DN, Jenkinson M (2011) A Bayesian model of shape and appearance for subcortical brain segmentation. Neuroimage 56:907-922. CrossRef Medline

Ramnani N, Behrens TE, Johansen-Berg H, Richter MC, Pinsk MA, Andersson JL, Rudebeck P, Ciccarelli O, Richter W, Thompson AJ, Gross CG, Robson MD, Kastner S, Matthews PM (2006) The evolution of prefrontal inputs to the cortico-pontine system: diffusion imaging evidence from Macaque monkeys and humans. Cereb Cortex 16:811-818. Medline

Ravizza SM, McCormick CA, Schlerf JE, Justus T, Ivry RB, Fiez JA (2006) Cerebellar damage produces selective deficits in verbal working memory. Brain 129:306-320. Medline

Ross G, Boatright S, Auld PA, Nass R (1996) Specific cognitive abilities in 2-year-old children with subependymal and mild intraventricular hemorrhage. Brain Cogn 32:1-13. CrossRef Medline

Salimi-Khorshidi G, Douaud G, Beckmann CF, Glasser MF, Griffanti L, Smith SM (2014) Automatic denoising of functional MRI data: combining independent component analysis and hierarchical fusion of classifiers. Neuroimage 90:449-468. CrossRef Medline

Salmi J, Pallesen KJ, Neuvonen T, Brattico E, Korvenoja A, Salonen O, Carlson S (2010) Cognitive and motor loops of the human cerebrocerebellar system. J Cogn Neurosci 22:2663-2676. CrossRef Medline

Salvan P, Froudist Walsh S, Allin MP, Walshe M, Murray RM, Bhattacharyya S, McGuire PK, Williams SC, Nosarti C (2014) Road work on memory lane-functional and structural alterations to the learning and memory circuit in adults born very preterm. Neuroimage 102:152-161. CrossRef Medline

Sansavini A, Guarini A, Alessandroni R, Faldella G, Giovanelli G, Salvioli G
(2007) Are early grammatical and phonological working memory abilities affected by preterm birth? J Commun Disord 40:239-256. CrossRef Medline

Seghier ML (2008) Laterality index in functional MRI: methodological issues. Magn Reson Imaging 26:594-601. CrossRef Medline

Ségonne F, Dale AM, Busa E, Glessner M, Salat D, Hahn HK, Fischl B (2004) A hybrid approach to the skull stripping problem in MRI. Neuroimage 22:1060-1075. CrossRef Medline

Ségonne F, Pacheco J, Fischl B (2007) Geometrically accurate topologycorrection of cortical surfaces using nonseparating loops. IEEE Trans Med Imaging 26:518-529. CrossRef Medline

Smith SM (2002) Fast robust automated brain extraction. Hum Brain Mapp 17:143-155. CrossRef Medline

Smith SM, Zhang Y, Jenkinson M, Chen J, Matthews PM, Federico A, De Stefano N (2002) Accurate, robust, and automated longitudinal and cross-sectional brain change analysis. Neuroimage 17:479-489. CrossRef Medline

Sowell ER, Peterson BS, Thompson PM, Welcome SE, Henkenius AL, Toga AW (2003) Mapping cortical change across the human life span. Nat Neurosci 6:309-315. CrossRef Medline

Stewart AL, Thorburn RJ, Hope PL, Goldsmith M, Lipscomb AP, Reynolds EO (1983) Ultrasound appearance of the brain in very preterm infants and neurodevelopmental outcome at 18 months of age. Arch Dis Child 58:598-604. CrossRef Medline

Sudlow CL, Warlow CP (1997) Comparable studies of the incidence of stroke and its pathological types: results from an international collaboration. International Stroke Incidence Collaboration. Stroke 28:491-499. CrossRef Medline

Thiebaut de Schotten M, Dell'Acqua F, Forkel SJ, Simmons A, Vergani F, Murphy DG, Catani M (2011) A lateralized brain network for visuospatial attention. Nat Neurosci 14:1245-1246. CrossRef Medline

Thiebaut de Schotten M, Dell'Acqua F, Valabregue R, Catani M (2012) Monkey to human comparative anatomy of the frontal lobe association tracts. Cortex 48:82-96. CrossRef Medline

Tournier JD, Calamante F, Gadian DG, Connelly A (2004) Direct estimation of the fiber orientation density function from diffusion-weighted MRI data using spherical deconvolution. Neuroimage 23:1176-1185. CrossRef Medline

Vestergaard M, Madsen KS, Baaré WF, Skimminge A, Ejersbo LR, Ramsøy TZ, Gerlach C, Akeson P, Paulson OB, Jernigan TL (2011) White matter microstructure in superior longitudinal fasciculus associated with spatial working memory performance in children. J Cogn Neurosci 23:21352146. CrossRef Medline

Wass SV, Scerif G, Johnson MH (2012) Training attentional control and working memory-is younger, better? Dev Rev 32:360-387. CrossRef

Winston GP, Stretton J, Sidhu MK, Symms MR, Thompson PJ, Duncan JS (2013) Structural correlates of impaired working memory in hippocampal sclerosis. Epilepsia 54:1143-1153. CrossRef Medline

Wolf SL, Winstein CJ, Miller JP, Taub E, Uswatte G, Morris D, Giuliani C, Light KE, Nichols-Larsen D, Nichols-Larsen D (2006) Effect of constraint-induced movement therapy on upper extremity function 3-9 months after stroke: the EXCITE randomized clinical trial. JAMA 296: 2095-2104. CrossRef Medline

Woodward LJ, Edgin JO, Thompson D, Inder TE (2005) Object working memory deficits predicted by early brain injury and development in the preterm infant. Brain 128:2578-2587. CrossRef Medline

Woolrich MW, Ripley BD, Brady M, Smith SM (2001) Temporal autocorrelation in univariate linear modeling of FMRI data. Neuroimage 14: 1370-1386. CrossRef Medline

Woolrich MW, Behrens TE, Beckmann CF, Jenkinson M, Smith SM (2004) Multilevel linear modelling for FMRI group analysis using Bayesian inference. Neuroimage 21:1732-1747. CrossRef Medline

Woolrich MW, Jbabdi S, Patenaude B, Chappell M, Makni S, Behrens T, Beckmann C, Jenkinson M, Smith SM (2009) Bayesian analysis of neuroimaging data in FSL. Neuroimage 45:S173-S186. CrossRef Medline

Worsley KJ (2001) Statistical analysis of activation images. In: Functional MRI: an introduction to methods (Jezzard P, Matthews PM, Smith SM, eds). Oxford, UK: Oxford UP.

Zhang Y, Brady M, Smith S (2001) Segmentation of brain MR images through a hidden Markov random field model and the expectationmaximization algorithm. IEEE Trans Med Imaging 20:45-57. CrossRef Medline 